Article

\title{
Impacts of Sociodemographic Characteristics and Cardinal Health Problems on Health-Related Quality of Life among Korean Older Adults
}

\author{
Sang-Dol Kim
}

Department of Nursing, College of Health Science, Kangwon National University, 346 Hwangjo-gil, Dogye-eup, Samcheok-si, Gangwon-do 25949, Korea; nu11110@kangwon.ac.kr

Received: 30 July 2020; Accepted: 14 September 2020; Published: 16 September 2020

\begin{abstract}
Background: Health-related quality of life is a critical health index for older adults. Objectives: The aim of this study was to identify the impacts of sociodemographic characteristics and cardinal health problems on health-related quality of life (HRQoL) among Korean older adults. Methods: Data were extracted from the 7th Korea National Health and Nutrition Examination Survey from 2018. The data were analyzed using SPSS 24.0, employing multiple linear regression with a complex sample design. Results: The overall mean score for HRQoL in the older Korean population was 0.89 points. HRQoL scores were significantly influenced by covariances adjusted for sociodemographic variables such as gender, age, marital status, and economic activities among Korean elderly $\left(R^{2}=0.110, p<0.001\right)$. They were also significantly influenced by covariances adjusted for cardinal health problems such as obesity, activity limitation, hypertension, diabetes mellitus, and hyperlipidemia among Korean older adults $\left(R^{2}=0.286, p<0.001\right)$; however, among the covariances, activity limitation was the only variable to significantly affect HRQoL among older Korean people $(p<0.001)$. Conclusions: The findings implied that public health policies and programs for HRQoL are needed to promote proper physical activity and devise tailored measures for targeted sociodemographic variables among Korean older adults.
\end{abstract}

Keywords: quality of life; older adults; activity limitation

\section{Introduction}

The aging population is increasing worldwide, and the aging of the older adult population is accelerating. According to the Korean Statistical Information Service (KOSIS), the proportion of adults aged 65 or older in Korea was $15.7 \%$ in 2020 and is expected to reach $33.9 \%$ in 2040 [1]. Japan ranked first with $28.4 \%$ of the global elderly population, followed by Italy with $23.3 \%$, Portugal with $22.8 \%$, Finland with $22.6 \%$, and Greece with $22.3 \%$ in 2020 [1].

A previous study suggested that, due to the continued increase in life expectancy, good health-related quality of life (HRQoL) among the aging population has become more important, and this topic is receiving increasing attention [2,3]. HRQoL generally refers to an individual's level of subjective satisfaction with life, in the context of their needs, interests, culture, and value system [4-6]. Older adults usually experience health problems in relation to physical health including "daily functional disabilities and metabolic diseases, sociopsychological health, and socioeconomic status due to the variety of life trajectories one can experience while aging" [4-7]. Therefore, older adults with daily functional disabilities or chronic diseases often wish to improve their HRQoL, and so it is necessary to evaluate the impacts of individual chronic diseases and sociodemographic factors on HRQoL $[3,5,6]$. 
Previous studies indicated that a health system for an aging population must be designed and adapted to meet the needs of older people to ensure that the best-quality care is delivered as efficiently as possible to enhance older adults' HRQoL $[5,8,9]$. Past studies also stressed that the longer-term cost-effectiveness of high-quality care for older adults will be dependent on the measurement and evaluation of outcomes that are highly valued by older people themselves [8,9]. One prior study insisted that HRQoL can be considered as a valuable health index for older adults [10]. This can be presumed to mean that an emphasis on HRQoL should be taken for granted when it comes to older adults.

Older adults generally tend to have cardinal health problems including chronic diseases and frailty [3,5]. According to the Korea Institute for Health and Social Affairs (KIHASA) [11], half of the Korean older adult population has three or more cardinal health problems such as hypertension, hyperlipidemia, diabetes mellitus, obesity, and activity limitation. Among the cardinal health problems, the chronic diseases are hypertension and dyslipidemia, and previous studies suggested that they affect HRQoL [12-14]. Moreover, hypertension leads to physical dysfunction and limited activity [12,15], and obesity, hypertension, and diabetes mellitus, or a combination of them, have been reported to be negatively associated with HRQoL [16,17]. Some previous studies explored the relationships between variable pairs such as gender differences in HRQoL in older adults and chronic diseases [16-19].

As stated, HRQoL may act as an indicator of high-quality care in older adults. Taken together, the previous studies imply that factors affecting HRQoL should be rigorously reviewed from multidimensional perspectives to increase HRQoL in the older adult population [17]. In this context, this study aims to identify the impacts of the sociodemographic characteristics and cardinal health problems reported by the Korea National Health and Nutrition Examination Survey (KNHANES) on HRQoL in Korean older adults.

\section{Materials and Methods}

\subsection{Design and Participants}

This was a secondary analysis study that used data extracted from the 2018 KNHANES by the Korea Centers for Disease Control and Prevention (KCDC) [20]. The sampling framework of the KNHANES entailed the use of population and housing census data available at the time of the most recent sample design. Through the KNHANES, data could be extracted to create a representative sample of target people aged $\geq 65$ years residing in the Republic of Korea. The survey zones excluded facilities for senior citizens, troops, prisons, and foreign households from the sample survey zones. The total number of study participants was 1609 subjects from Korea's aging population.

\subsection{Ethical Considerations}

The KNHANES VII-3 was approved by the Institutional Review Board of the KCDC (2018-01-03-P-A) [20]. The raw data used in this study were obtained through the KNHANES website under the KCDC. In this study, personal information was fully anonymized. The informed consent of the participants was not required for this study.

\subsection{Instruments}

\subsubsection{Health Related Quality of Life}

The KNHANES entailed an investigation of household members, the administration of health and nutrition surveys, and health screenings. The HRQoL survey was administered through interviews at the mobile screening center. The interview was conducted by the health survey team of the KCDC. Professional investigators of the health survey team are composed of nurses, nutritionists, and health science majors, etc. After being selected, they are put into the investigation site after completing education and practice for 2 to 4 weeks. After that, the ability to conduct investigations is continuously 
verified through regular training ( 7 times a year) and on-site quality management. This study used data on HRQoL, measured with the EuroQoL 5-dimension (EQ-5D) standardized questionnaire, which is a comprehensive and descriptive indicator of five dimensions of HRQoL. The five dimensions of this model are mobility, self-care, usual activities, pain/discomfort, and anxiety/depression. The survey of the EQ-5D index was conducted with the approval of the EuroQol Group (www.euroqol.org). The EQ-5D index was in turn converted into a utility score to summarize the data from the survey of EQ-5D [2,20]. The utility score was generated by KCDC according to the criteria of the EuroQol Group [20]. The limit values of the scale were set at a score of 1 , which means a full health state, and 0 , which means a state as bad as being dead $[2,20,21]$. According to prior studies, the EQ-5D index has been adjusted for sociodemographic factors and clinical health conditions $[2,21,22]$.

\subsubsection{Sociodemographic Characteristics}

The following sociodemographic characteristics were considered: sex, age group, marital status, and economic activities. Age group was divided into three categories: 65 to 70 years old, 71 to 75 years old, and 76 years and older. Marital status was divided into four categories: with partner, without partner, divorce, and bereavement. Economic activities was categorized into yes and no.

\subsubsection{Cardinal Health Problems}

Based on data from the KOSIS, KIHASA, and KNHANES, in order of highest incidence rate out of chronic diseases and health problems, cardinal health problems were considered as follows: obesity (BMI $\geq 25$ ), hypertension, activity limitation (which means restriction of daily life and social activities due to current health problems or physical or mental disorders [20]), diabetes mellitus, and dyslipidemia. Cardinal health problems were categorized into yes and no.

\subsection{Data Analysis}

The data for analysis were extracted using the multi-stage stratification probability extraction method, which is a complex sample design method, and the analysis plan file was created by designating the complex sample design elements, such as hierarchy (layer variables), cluster (collection variables), and sample weight (weight variables) for representative samples [20]. The weights were corrected for "inclusion errors, unequal extraction rates, and non-responding errors of participants who were not included in the survey" [20]. Therefore, the analysis data increased "the representativeness and accuracy of estimates of prevalence rates" related to sociodemographic factors and health problems in the target population [20].

This study analyzed the results of the elderly population aged 65 or older, which was the group of interest in this study, by making the entire data an analysis database and creating variables that distinguished the group of subjects aged 65 or older from the other groups ( 65 years old or older $=1$, selected, other groups $=0$, not selected), and designating the group of senior citizens as a parent group. The processing of missing data was carried out with valid values and only affected the dispersion of estimates, including those with effects on the variables analyzed. Sociodemographic characteristics, cardinal health problems, and the HRQoL score were determined by analyzing the frequency of complex samples and the descriptive statistics. The factors related to cardinal health problems that had an effect on the HRQoL were examined via a covariance analysis of multiple linear regressions with a complex sample design. For all tests, the statistics package used was SPSS version 24, and the confidence and significance levels were set at $95 \%$ and 0.05 , respectively.

\section{Results}

The findings are presented in Tables 1 and 2. The total number of study participants was 1609 people aged $\geq 65$ years. The gender ratio was $57.3 \%$ women to $42.7 \%$ men. The overall mean score for the HRQoL in the older Korean population was 0.89 points. Among the sociodemographic characteristics, women tended to have a lower score for HRQoL than men $(p<0.05)$. The score of HRQoL was 
lower in the older age group than the comparison groups $(p<0.001)$, higher among older adults and their partners than among those who experienced bereavement $(p<0.05)$, and unemployed older adults tended to have a lower HRQoL score than the employed $(p<0.05)$. Scores on the HRQoL were significantly influenced by covariances adjusted for sociodemographic variables such as gender, age, marital status, and economic activities among older adults $\left(R^{2}=0.110, p<0.001\right)$. They were also significantly influenced by covariances adjusted for cardinal health problems such as obesity, activity limitation, hypertension, diabetes mellitus, and hyperlipidemia among older adults $\left(R^{2}=0.286\right.$, $p<0.001$ ); however, of the covariances, activity limitation was the only significant variable affecting the HRQoL of older Koreans $(p<0.001)$.

Table 1. Sociodemographic characteristics and cardinal health problems among Korean older adults.

\begin{tabular}{|c|c|c|c|}
\hline Variables & $\mathbf{N}$ & $\%$ & SE \\
\hline Overall & 1609 & 100.0 & 0.0 \\
\hline \multicolumn{4}{|c|}{ Socioeconomic factors } \\
\hline Male & 684 & 42.7 & 1.2 \\
\hline Female & 925 & 57.3 & 1.2 \\
\hline \multicolumn{4}{|l|}{ Age group } \\
\hline $65-70$ & 597 & 37.8 & 1.8 \\
\hline $71-75$ & 417 & 24.2 & 1.3 \\
\hline$\geq 76$ & 595 & 38.0 & 1.7 \\
\hline \multicolumn{4}{|l|}{ Marital status } \\
\hline With partner & 939 & 65.6 & 1.7 \\
\hline Without partner & 7 & 0.6 & 0.3 \\
\hline Divorce & 436 & 30.0 & 1.5 \\
\hline Bereavement & 56 & 3.8 & 0.7 \\
\hline \multicolumn{4}{|l|}{ Economic activities } \\
\hline Yes & 524 & 33.4 & 1.5 \\
\hline No & 996 & 66.6 & 1.5 \\
\hline \multicolumn{4}{|c|}{ Cardinal health problems } \\
\hline \multicolumn{4}{|c|}{ Obesity $(\mathrm{BMI} \geq 25)$} \\
\hline No & 965 & 61.9 & 1.5 \\
\hline Yes & 612 & 38.1 & 1.5 \\
\hline \multicolumn{4}{|l|}{ Activity limitation } \\
\hline No & 1266 & 83.9 & 1.3 \\
\hline Yes & 266 & 16.1 & 1.3 \\
\hline \multicolumn{4}{|l|}{ Hypertension } \\
\hline No & 29 & 2.7 & 0.7 \\
\hline Yes & 888 & 97.3 & 0.7 \\
\hline \multicolumn{4}{|l|}{ Diabetes Mellitus } \\
\hline No & 8 & 3.5 & 1.6 \\
\hline Yes & 339 & 96.5 & 1.6 \\
\hline \multicolumn{4}{|l|}{ Hyperlipidemia } \\
\hline No & 77 & 13.5 & 1.7 \\
\hline Yes & 496 & 86.5 & 1.7 \\
\hline
\end{tabular}

Abbreviations: BMI, body mass index; CI, confidence interval; EQ-5D, EuroQol-5dimension; SE, standard error. 
Table 2. Regressions of EQ-5D index scores according to sociodemographic characteristics and major health problems among Korean older adults.

\begin{tabular}{|c|c|c|c|c|c|c|c|c|c|c|}
\hline \multirow[t]{2}{*}{ Variables } & \multirow[t]{2}{*}{ B } & \multirow[t]{2}{*}{ SE } & \multirow[t]{2}{*}{$\beta$} & \multirow[t]{2}{*}{ SE } & \multicolumn{2}{|c|}{$95 \% C I$} & \multirow[t]{2}{*}{$t$} & \multirow[t]{2}{*}{$d f$} & \multirow[t]{2}{*}{$p$} & \multirow[t]{2}{*}{$R^{2}$} \\
\hline & & & & & Lower & Upper & & & & \\
\hline Overall & 0.89 & 0.005 & & & & & & & & \\
\hline $\begin{array}{l}\text { Sociodemographic } \\
\text { factors }\end{array}$ & & & & & & & & & & 0.117 \\
\hline Intercept & & & 0.796 & 0.029 & 0.737 & 0.854 & 27.053 & 159 & 0.000 & \\
\hline $\begin{array}{c}\text { Sex } \\
\text { Male } \\
\text { Female }\end{array}$ & $\begin{array}{l}0.92 \\
0.86 \\
\end{array}$ & $\begin{array}{l}0.006 \\
0.008 \\
\end{array}$ & $\begin{array}{c}0.027 \\
0.000^{a}\end{array}$ & 0.009 & 0.009 & 0.044 & 3.049 & 159 & 0.003 & \\
\hline $\begin{array}{l}\text { Age group } \\
65-70 \\
71-75 \\
\geq 76 \\
\end{array}$ & $\begin{array}{l}0.92 \\
0.91 \\
0.83\end{array}$ & $\begin{array}{l}0.005 \\
0.007 \\
0.011\end{array}$ & $\begin{array}{c}0.069 \\
0.059 \\
0.000^{a}\end{array}$ & $\begin{array}{c}0.01 \\
0.011\end{array}$ & $\begin{array}{l}0.048 \\
0.038\end{array}$ & $\begin{array}{c}0.089 \\
0.08\end{array}$ & $\begin{array}{l}6.544 \\
5.614\end{array}$ & $\begin{array}{l}159 \\
159\end{array}$ & $\begin{array}{l}0.000 \\
0.000\end{array}$ & \\
\hline $\begin{array}{c}\text { Marital status } \\
\text { With partner } \\
\text { Without partner } \\
\text { Divorce } \\
\text { Bereavement }\end{array}$ & $\begin{array}{l}0.91 \\
0.86 \\
0.84 \\
0.85\end{array}$ & $\begin{array}{l}0.005 \\
0.031 \\
0.012 \\
0.028\end{array}$ & $\begin{array}{c}0.059 \\
0.052 \\
0.026 \\
0.000^{\mathrm{a}} \\
\end{array}$ & $\begin{array}{l}0.027 \\
0.039 \\
0.028\end{array}$ & $\begin{array}{l}0.007 \\
-0.025 \\
-0.03\end{array}$ & $\begin{array}{l}0.112 \\
0.128 \\
0.082\end{array}$ & $\begin{array}{l}2.225 \\
1.333 \\
0.909\end{array}$ & $\begin{array}{l}159 \\
159 \\
159\end{array}$ & $\begin{array}{l}0.027 \\
0.184 \\
0.365\end{array}$ & \\
\hline $\begin{array}{c}\text { Economic activities } \\
\text { Yes } \\
\text { No }\end{array}$ & $\begin{array}{l}0.92 \\
0.87\end{array}$ & $\begin{array}{l}0.006 \\
0.007\end{array}$ & $\begin{array}{c}0.027 \\
0.000^{a}\end{array}$ & 0.008 & 0.011 & 0.043 & 3.316 & 159 & 0.001 & \\
\hline $\begin{array}{l}\text { Cardinal health } \\
\text { problems }\end{array}$ & & & & & & & & & & 0.286 \\
\hline Intercept & & & 0.897 & 0.016 & 0.864 & 0.93 & 55.027 & 64 & 0.000 & \\
\hline Obesity (BMI $\geq 25$ ) & & & & & & & & & & \\
\hline $\begin{array}{l}\text { No } \\
\text { Yes }\end{array}$ & $\begin{array}{l}0.79 \\
0.78\end{array}$ & $\begin{array}{l}0.042 \\
0.043\end{array}$ & $\begin{array}{c}0.016 \\
0.000^{\mathrm{a}}\end{array}$ & 0.023 & -0.03 & 0.062 & 0.681 & 64 & 0.499 & \\
\hline $\begin{array}{c}\text { Activity limitation } \\
\text { Yes } \\
\text { No }\end{array}$ & $\begin{array}{l}0.68 \\
0.89\end{array}$ & $\begin{array}{l}0.054 \\
0.033\end{array}$ & $\begin{array}{l}-0.217 \\
0.000^{a}\end{array}$ & 0.036 & -0.29 & -0.145 & -6.011 & 64 & 0.000 & \\
\hline $\begin{array}{c}\text { Hypertension } \\
\text { No } \\
\text { Yes }\end{array}$ & $\begin{array}{l}0.88 \\
0.87\end{array}$ & $\begin{array}{l}0.031 \\
0.008\end{array}$ & $\begin{array}{c}-0.05 \\
0.000^{\mathrm{a}}\end{array}$ & 0.045 & -0.14 & 0.039 & -1.125 & 64 & 0.265 & \\
\hline $\begin{array}{c}\text { Diabetes Mellitus } \\
\text { No } \\
\text { Yes }\end{array}$ & $\begin{array}{l}0.81 \\
0.76\end{array}$ & $\begin{array}{c}0.055 \\
0.04\end{array}$ & $\begin{array}{c}0.045 \\
0.000^{\mathrm{a}}\end{array}$ & 0.049 & -0.053 & 0.144 & 0.918 & 64 & 0.362 & \\
\hline $\begin{array}{c}\text { Hyperlipidemia } \\
\text { No } \\
\text { Yes }\end{array}$ & $\begin{array}{l}0.77 \\
0.79\end{array}$ & $\begin{array}{l}0.06 \\
0.03\end{array}$ & $\begin{array}{l}-0.019 \\
0.000^{\mathrm{a}}\end{array}$ & 0.048 & -0.115 & 0.076 & -0.402 & 64 & 0.689 & \\
\hline
\end{tabular}

Abbreviations: BMI, body mass index; CI, confidence interval; EQ-5D, EuroQol-5dimension; SE, standard error. Notes: ${ }^{a}$, referent group was adjusted by considering it as the most vulnerable group within each independent variable. The overall mean score for health-related quality of life (HRQoL) in the older Korean population was 0.89 points. HRQoL scores were significantly influenced by covariances adjusted for sociodemographic variables such as gender, age, marital status, and economic activities among Korean elderly $\left(R^{2}=0.110, p<0.001\right)$. They were also significantly influenced by covariances adjusted for cardinal health problems such as obesity, activity limitation, hypertension, diabetes mellitus, and hyperlipidemia among Korean older adults $\left(R^{2}=0.286, p<0.001\right)$; however, among the covariances, activity limitation was the only variable to significantly affect HRQoL among older Korean people $(p<0.001)$. 


\section{Discussion}

As shown by the results, the overall mean score on the HRQoL among Korea's aging population was similar to the scores reported in previous studies on US populations [23,24]. The score found in this study was also slightly higher than those of older adults in England [25] and Canada [26]. In contrast to these findings, the mean HRQoL score of older adults in Hong Kong was higher than that of our subjects [14]. This implies that the HRQoL of the older adult population in Korea is similar to that in Eastern and Western countries.

In order to confirm the determinants influencing HRQoL scores among older adult Koreans, based on previous research results $[3,5,6,8,14,27,28]$, related factors and medical variables such as cardinal health problems were included. These variables were also included as influencing factors and were subjected to a linear regression analysis with a complex sample design.

Among the sociodemographic characteristics, the HRQoL score was significantly affected by covariances adjusted for gender, age group $\geq 65$, marital status, and economic activities. Among these influencing factors, women tended to have a lower score for HRQoL than men, and this finding is similar to those reported in previous studies in the UK, India, China, and Europe [2,7,19,29].

Among the age groups, the score of the HRQoL was lower in the older age group than the comparison groups, which was consistent with the results of previous studies in Singapore and Europe $[2,5,29]$.

Among the marital status variables, the HRQoL score was higher among older adults and their partners than among those who experienced bereavement. These findings are similar to those reported in a previous study in Europe [29]. Health policies to ensure high-quality care should focus on measures to improve the HRQoL for these bereaved older adults.

Among the employment status variables, unemployed older adults tended to have a lower HRQoL score than the employed, and this finding is similar to those reported in previous studies [2,29].

As stated, the findings show that the impacts of sociodemographic characteristics on HRQoL in older adults tend to be similar in the East and West. These findings will also provide evidence that can be used to develop tailored measures for elderly Koreans who are vulnerable to low HRQoL [30].

The HRQoL score of Korea's aging population was significantly influenced by covariances adjusted for obesity, activity limitation, hypertension, diabetes mellitus, and hyperlipidemia. However, interestingly, activity limitation was the only variable that significantly affected HRQoL among Korea's aging population. That is, in the present study, the HRQoL score of physically inactive older adults was significantly lower than that of those without limited activity. Of these findings, the activity limitation variable was incompatible with previous research findings from the Netherlands, in which physical function did not have a direct effect on HRQoL [31].

In contrast, the HRQoL scores of Korea's aging population with physical inactivity were similar to those of previous studies in aging populations with physical disability in Hong Kong [14], people aged 80 in Shanghai [32], and Dutch older people [33].

The present findings also support the notion that major health problems could cause an impairment in activities of daily living in older adults [26,34]. Moreover, these findings stress that health care professionals in particular should focus on improving physical activity in older adults with limited activity [34].

Unlike the present findings, one previous study reported that the aging population with hypertension was generally more vulnerable to the deterioration of HRQoL due to related comorbidities and physical disabilities [14]. It can be estimated that hypertension is a variable that negatively affects older adults' HRQoL [14], implying that it should be regularly managed to mitigate its negative effects.

These results are in line with the findings on factors influencing HRQoL among very old adult individuals in Switzerland, in particular with the findings on the functional health dimension [35].

Hypertension is also one of the major comorbidities related to hyperlipidemia. Hyperlipidemia increases the risk of cardiovascular diseases such as hypertension [36], significantly compromising HRQoL [13]; therefore, aggressive lipid management is needed for older adults [12]. 
Unlike the present findings, some previous findings suggested that obesity and diabetes in older adults are the most decisive factors that adversely affect HRQoL $[2,16]$. However, in the present study, except for the activity limitation variable, after adjusting other covariances such as hypertension, dyslipidemia, diabetes mellitus, and obesity, cardinal health problems did not act as significant affected factors related to HRQoL in Korean older adults. These findings may help design health policies that target HRQoL among the older Korean population [17].

As stated, previous studies have argued that hypertension and hyperlipidemia affect HRQoL. Hypertension leads to physical dysfunction, and furthermore, obesity and diabetes are major factors that negatively affect older adults' HRQoL $[2,14,16]$. Meanwhile, the results of this study differed from previous studies in which major health variables such as hypertension, hyperlipidemia, obesity, and diabetes had direct negative impacts on the HRQoL of older adults. In other words, the variables in those studies did not directly affect HRQoL except for the activity limitation variable. This discrepancy can be attributed to a tendency for older adults in Korea to often experience three or more chronic diseases as they get older, as attested to by the KOSIS report. This is why chronic diseases did not directly affect Korean older adults' HRQoL; instead, the restriction of activity can be interpreted as playing an important role in their HRQoL. Therefore, proper health policies are needed to prevent the further deterioration of physical activity due to related cardinal health problems.

The strengths of this study lie in its rigorous methodology; the study tried to increase the representativeness and accuracy of the estimates of prevalence rates and factors affecting HRQoL, and cardinal health problems in the Korean older population, by using a complex sample design. Also, the KNHANES data were sufficiently rigorous to enable comparisons across countries and to be used for health policy development. Furthermore, this study is significant because it secured evidence that can be used to devise measures targeting older people who are vulnerable to poor HRQoL. It is necessary to investigate how to improve the HRQoL of older Koreans in the future. A follow-up survey is needed to confirm the changes in HRQoL related to activity limitation.

\section{Conclusions}

In conclusion, HRQoL scores in Korea's aging population were significantly influenced by socioeconomic factors including gender, age, marital status, and economic activities. In particular, the HRQoL score was more vulnerable in women, older ages, the widowed, and the elderly who did not engage in economic activities than the comparison group. Future studies should assess the evidence that women are more vulnerable than men to deteriorated HRQoL. Of the covariances adjusted for some cardinal health problems, activity limitation was the only variable to directly and significantly affect HRQoL among Korean older adults. The findings implied that public health policies and programs for HRQoL are needed to promote proper physical activity and devise tailored measures for targeted sociodemographic variables among Korean older adults.

Funding: This study received no research funding.

Acknowledgments: The data for this study were extracted from the 7th Korea National Health and Nutrition Examination Survey (KNHANES VII-3), 2018, by the Korea Centers for Disease Control and Prevention.

Conflicts of Interest: The author declares no conflict of interest.

\section{References}

1. Korean Statistical Information Service. International Statistics: Dependency Ratio and Aging Index. Available online: https://kosis.kr/eng/ (accessed on 10 September 2020).

2. Barton, G.R.; Sach, T.H.; Doherty, M.; Avery, A.J.; Jenkinson, C.; Muir, K.R. An assessment of the discriminative ability of the EQ-5D index, SF-6D, and EQ VAS, using sociodemographic factors and clinical conditions. Eur. J. Health Econ. 2008, 9, 237-249. [CrossRef] [PubMed] 
3. Christopher, O.A.; Ukamaka, G.M.; Fatai, A.M.; Emmanuel, C.O.; Ifeanyi, C.U.; Adesola, O. Depression, functional disability and quality of life among Nigerian older adults: Prevalence and relationships. Arch. Gerontol. Geriatr. 2018, 74, 39-43.

4. Golubeva, E.Y. The role of social-medical care in enhancing the quality of life of elderly people in the Russian part of the Barents-Euroarctic region. Adv. Gerontol. 2014, 4, 264-268. [CrossRef]

5. Ge, L.; Ong, R.; Yap, C.W.; Heng, B.H. Effects of chronic diseases on health-related quality of life and self-rated health among three adult age groups. Nurs. Health Sci. 2019, 21, 214-222. [CrossRef] [PubMed]

6. Hewaratne, D.W.T.D.; Foong, M.M.; Khatijah, L.A.; Samath, D.D. Health related quality of life and its associated factors among community-dwelling older people in Sri Lanka: A cross-sectional study. Arch. Gerontol. Geriatr. 2018, 76, 215-220.

7. Himanshu, H.; Arokiasamy, P.; Talukdar, B. Illustrative effects of social capital on health and quality of life among older adult in India: Results from WHO-SAGE India. Arch. Gerontol. Geriatr. 2019, 82, $15-21$. [CrossRef]

8. Bjerk, M.; Brovold, T.; Skelton, D.A.; Bergland, A. Associations between health-related quality of life, physical function and fear of falling in older fallers receiving home care. BMC Geriatr. 2018. [CrossRef]

9. Catherine, M.M.; Ruth, W.; Mary, A.L.; Lancsar, E.; Kaambwa, B.; Ratcliffe, J. How important is health status in defining quality of life for older people? An exploratory study of the views of older South Australians. Appl. Health Econ. Health Policy 2014, 12, 73-84.

10. Leung, K.K.; Wu, E.C.; Lue, B.H.; Tang, L.Y. The use of focus groups in evaluating quality of life components among elderly Chinese people. Qual. Life Res. 2004, 13, 179-190. [CrossRef] [PubMed]

11. Korea Institute for Health and Social Affairs. 2017 Elderly Survey. Available online: https://www.kihasa.re. kr/web/publication/research/view.do (accessed on 9 February 2020).

12. Chen, C.Y.; Lee, C.W.; Chien, S.C.; Su, M.I.; Lin, S.I.; Cheng, C.W.; Hung, T.C.; Yeh, H.L. Dyslipidemia management for elderly people with metabolic syndrome: A mini-review. Int. J. Gerontol. 2018, 12, 7-11. [CrossRef]

13. Park, H.J. The impact of dyslipidemia on the health-related quality of life of Korean females aged 50 years and older. Iran. J. Public Health 2019, 48, 556-558. [CrossRef] [PubMed]

14. Wong, E.L.Y.; Xu, R.H.; Cheung, A.W.L. Health-related quality of life among patients with hypertension: Population-based survey using EQ-5D-5L in Hong Kong SAR, China. BMJ Open 2019, 27, e032544. [CrossRef] [PubMed]

15. Dritsaki, M.; Petrou, S.; Williams, M.; Lamb, S.E. An empirical evaluation of the SF-12, SF-6D, EQ-5D and Michigan hand outcome questionnaire in patients with rheumatoid arthritis of the hand. Health Qual. Life Outcomes 2017, 24, 20. [CrossRef]

16. Busutil, R.; Espallardo, O.; Torres, A.; Martínez-Galdeano, L.; Zozaya, N.; Hidalgo-Vega, Á. The impact of obesity on health-related quality of life in Spain. Health Qual. Life Outcomes 2017, 15, 197. [CrossRef] [PubMed]

17. Park, B.; Ock, M.; Lee, H.A.; Lee, S.; Han, H.; Jo, M.W.; Park, H. Multimorbidity and health-related quality of life in Koreans aged 50 or older using KNHANES 2013-2014. Health Qual. Life Outcomes 2018, 16, 186. [CrossRef] [PubMed]

18. Ko, H.N.; Park, Y.H.; Cho, B.L.; Lim, K.C.; Ryu, S.I. Gender differences in health status, quality of life, and community service needs of older adults living alone. Arch. Gerontol. Geriatr. 2019, 83, 239-245. [CrossRef] [PubMed]

19. Li, Y.M.; Jiang, C.; He, L.; Li, X.X.; Hou, X.X.; Chang, S.S.; Lip, G.Y.H.; Du, X.; Dong, J.Z.; Ma, C.S. Sex differences in presentation, quality of life, and treatment in Chinese atrial fibrillation patients: Insights from the China atrial fibrillation registry study. Med. Sci. Monit. 2019, 25, 8011-8018. [CrossRef]

20. Korea Centers for Disease Control and Prevention. Survey Data. Available online: https://knhanes.cdc.go.kr/ knhanes/sub03/sub03_02_02.do (accessed on 30 March 2020).

21. Parkin, D.; Devlin, N.; Feng, Y. What determines the shape of an EQ-5D index distribution? Med. Decis. Mak. 2016, 36, 941-951. [CrossRef]

22. Liang, L.; Alex, Z.F. Some methodological issues with the analysis of preference-based EQ-5D index score. Health Serv. Outcomes Res. Method 2009, 9, 162-176. 
23. Lubetkin, E.I.; Jia, H.; Franks, P.; Gold, M.R. Relationship among socio-demographic factors, clinical conditions, and health-related quality of life: Examining the EQ-5D in the U.S. general population. Qual. Life Res. 2005, 14, 2187-2196. [CrossRef]

24. Nan, L.; Yu, K.; Jeffrey, A.J.; Coons, S.J. The association of survey language (Spanish vs. English) with Health Utilities Index and EQ-5D index scores in a United States population sample. Qual. Life Res. 2009, 18, 1377-1385.

25. Wu, M.; Brazier, J.E.; Kearns, B.; Relton, C.; Smith, C.; Cooper, C.L. Examining the impact of 11 longstanding health conditions on health-related quality of life using the EQ-5D in a general population sample. Eur. J. Health Econ. 2015, 16, 141-151. [CrossRef] [PubMed]

26. Tawiah, A.K.; Sayah, F.; Ohinmaa, A.; Johnson, J.A. Discriminative validity of the EQ-5D-5 L and SF-12 in older adults with arthritis. Health Qual. Life Outcomes 2019, 17, 68. [CrossRef] [PubMed]

27. Fong, J.H. Disability incidence and functional decline among older adults with major chronic diseases. BMC Geriatr. 2019, 19, 323. [CrossRef]

28. Liu, H.Y.; Tsai, W.C.; Chiu, M.J.; Tang, L.Y.; Lee, H.J.; Shyu, Y.L. Mild cognitive impairment in combination with comorbid diabetes mellitus and hypertension is negatively associated with health-related quality of life among older persons in Taiwan. Qual. Life Res. 2019, 28, 1281-1291. [CrossRef] [PubMed]

29. Schorr, A.V.; Khalaila, R. Aging in place and quality of life among the elderly in Europe: A moderated mediation model. Arch. Gerontol. Geriatr. 2018, 77, 196-204. [CrossRef]

30. Zúñiga, M.P.; García, R.; Araya, A.X. Quality of life among frail older people. Rev. Méd. Chile 2019, 147, 870-876. [CrossRef]

31. Bielderman, A.; de Greef, M.H.G.; Krijnen, W.P.; van der Schans, C.P. Relationship between socioeconomic status and quality of life in older adults: A path analysis. Qual. Life Res. 2015, 24, 1697-1705. [CrossRef]

32. Sun, S.Y.; Guo, Y.F.; Ruan, Y.; Zheng, Y.; Huang, Z.Z.; Shi, Y.; Wu, F. Association between quality of life and physical activity among people aged 50 years and over. Zhonghua Liu Xing Bing Xue Za Zhi 2019, 40, 1245-1251. [CrossRef]

33. Gobbens, R.J.J.; van Assen, M.A.L.M. Associations between multidimensional frailty and quality of life among Dutch older people. Arch. Gerontol. Geriatr. 2017, 73, 69-76. [CrossRef]

34. Park, S.W.; Ryu, J.M.; Lee, M.J. Quality of life in older adults with Benign Prostatic hyperplasia. Healthcare 2020, 8, 158. [CrossRef] [PubMed]

35. Christophe, L.; Christine, C.; Anne-Françoise, A.; Herrmann, F.R.; Ludwig, C. Health status and quality of life: Results from a national survey in a community-dwelling sample of elderly people. Qual. Life Res. 2015, 24, 1687-1696.

36. Otsuka, T.; Takada, H.; Nishiyama, Y.; Kodani, E.; Saiki, Y.; Kato, K.; Kawada, T. Dyslipidemia and the risk of developing hypertension in a working-age male population. J. Am. Heart Assoc. 2016, 5, e003053. [CrossRef] 